\title{
Pharmacological characterization of venoms from three theraphosid spiders: Poecilotheria regalis, Ceratogyrus darlingi and Brachypelma epicureanum
}

Alejandro García-Arredondo*, Luis Rodríguez-Rios, Luis Fernando Díaz-Peña and Ricardo Vega-Ángeles

\begin{abstract}
Background: Tarantulas (Theraphosidae) represent an important source of novel biologically active compounds that target a variety of ion channels and cell receptors in both insects and mammals. In this study, we evaluate and compare the pharmacological activity of venoms from three taxonomically different theraphosid spiders bred in captivity: Poecilotheria regalis, an aggressive arboreal tarantula from southeastern India; Ceratogyrus darlingi, an aggressive tarantula from southern Africa; and Brachypelma epicureanum, a docile tarantula from the Yucatan dry forest of Mexico. Prior to this study, no research had been conducted with regard to the composition and pharmacological activity of these venoms.
\end{abstract}

Methods: The pharmacological characterization of the venoms was described for the first time by the assessment of their toxicity in crickets $\left(L D_{50}\right)$ along with their nociceptive (by using the formalin test), hyaluronidase, phospholipase $A_{2}$, edematogenic and caseinolytic activity.

Results: $P$. regalis and B. epicureanum venoms induced a similar lethal effect on crickets $\left(L D_{50}=5.23 \pm 3.1\right.$ and $14.4 \pm 5.0 \mu \mathrm{g}$ protein/g $48 \mathrm{~h}$ post-injection, respectively), whereas C. darlingi venom (119.4 $\pm 29.5 \mu \mathrm{g}$ protein $/ \mathrm{g}$ $48 \mathrm{~h}$ post-injection) was significantly less lethal than the other two venoms. All three venoms induced similar edematogenic activity on rats but did not induce nociceptive behavior. The assessment of enzymatic activity indicated that $P$. regalis venom induces significantly higher hyaluronidase activity $(27.6 \pm 0.9 \mathrm{TRU} / \mathrm{mg})$ than both $C$. darlingi ( $99.7 \pm 1.9 \mathrm{TRU} / \mathrm{mg})$ and B. epicureanum $(99.6 \pm 1.6 \mathrm{TRU} / \mathrm{mg})$; these latter venoms did not display phospholipase $\mathrm{A}_{2}$ or caseinolytic activity.

Conclusions: This study demonstrates that these theraphosid spiders of different habitats produce venoms with different activities. P. regalis venom displays a high level of hyaluronidase activity, which may be associated with its potentially medically significant bite.

Keywords: Poecilotheria regalis, Ceratogyrus darlingi, Brachypelma epicureanum, Tarantula, Venom, Toxicity

\footnotetext{
* Correspondence: alejandro.gr@uaq.mx

Laboratory of Chemical and Pharmacological Natural Product Research,

School of Chemistry, Autonomous University of Querétaro (UAQ), Santiago

de Querétaro, Querétaro, Mexico
} 


\section{Background}

The Theraphosidae family (phylum Arthropoda, class Arachnida, order Araneae, suborder Mygalomorphae) is a sizable group of large spiders that are also called tarantulas. Their venoms are mainly composed of peptides and proteins that target a variety of ion channels and cell receptors in both insects and mammals. Other components usually found in their venoms are nucleotides, free amino acids, neurotransmitters, polyamines and salts [1]. Due to the diverse mixture of components, tarantula venoms represent an important source of novel biologically active compounds that are potentially valuable for the development of therapeutic agents, tools for pharmacological research, and insecticidal peptides for potential use in agriculture [2-4].

To date, approximately 975 species of tarantulas (in 128 genera) have been recognized, which are found in several ecological niches worldwide, and it can be expected that many new species have yet to be described [5]. A total of 226 proteinaceous toxin sequences have been described to date from approximately 20 theraphosid species, the majority of which are small peptides that are ion-channel modulators [6]. Therefore, there is a significant interest in the study of the venoms of Theraphosidae species, not only because they constitute a potential source of valuable biomolecules, but also because they represent a large group that is relatively unexplored. In addition, the considerable size of these spiders permits easier venom extraction.

Tarantulas have become popular pets and the availability of several species has been facilitated by captive breeding. In this work, we focus on the pharmacological activity of the venoms from three taxonomically different theraphosid spiders widely kept and bred in captivity: two Old World tarantulas (Poecilotheria regalis and Ceratogyrus darlingi) and a new world tarantula (Brachypelma epicureanum). $P$. regalis, commonly referred to as the "Indian ornamental tree spider", is an arboreal tarantula from southeastern India and it is considered aggressive and very fast. It is also one of the most popular tarantulas for collectors. C. darlingi, commonly called the African rear-horned Baboon, is an aggressive tarantula from southern Africa. Its venom is believed to be no more than mildly toxic to humans and it is the most common Ceratogyrus species held in captivity [5]. Finally, B. epicureanum is a tarantula from the Yucatan dry forest of Mexico and it is considered nonaggressive [5, 7].

In general, tarantulas are not harmful to humans and there is no record of human deaths resulting from a bite by these spiders $[1,8]$. However, it is clear that some venoms are more toxic than others and may cause serious discomfort that might persist for several days. Some reports of tarantula bites suggest that the toxicity of Old World species is higher than that of the New World species, especially the members of the genus Poecilotheria
$[9,10]$. In a recent review of the literature on bites of species of this genus, it was found that a delayed onset of severe muscle cramps lasting for days is characteristic of Poecilotheria bites; other registered symptoms were local swelling, erythema, and moderate to severe pain [11].

Prior to this study, there had been no research conducted regarding the composition and pharmacological activity of the venoms of $P$. regalis, $C$. darlingi, and B. epicureanum. Thus, the aim of the current work was to provide quantitative information on the toxicology of these venoms in order to determine their pharmacological potential.

\section{Methods \\ Reagents}

Hyaluronic acid sodium salt from Streptococcus equi, hyaluronidase from bovine testes type IV-S, hexadecyltrimethylammonium bromide, protease from Streptomyces griseus, and carrageenan were purchased from Sigma (USA). Refined chemicals used for buffer preparations were purchased from J. T. Baker (USA). All reagents used in the determination of protein concentration and electrophoretic analysis were obtained from Bio-Rad (USA).

\section{Spiders}

The adult female spiders $(80-90 \mathrm{~mm})$ bred in captivity used in this work were obtained from the Mexican Department of the Environment and Natural ResourcesManagement and Preservation Unit (SEMARNATUMA-IN-0062-JAL). All spiders were kept individually in plastic containers with water ad libitum and were fed weekly with crickets (Acheta domestica).

\section{Venom extraction}

The spiders were immobilized by placing them in a small receptacle in a chloroform atmosphere for $15 \mathrm{~min}$ and then they were attached by the cephalothorax to a hand-made holder. The fangs were raised and positioned in a $1.5 \mathrm{~mL}$ microcentrifuge tube, ensuring that there was not any contamination with digestive fluids and saliva. Then, electrostimulation was applied with a pair of modified electrodes using an electrophoresis power supply (PowerPac Basic Power Supply Bio-Rad, USA) at 10-15 V. Electrodes were positioned within the fissure between the chelicerae and the cephalothorax, and stimulus was applied for two seconds with a three-second interval between shocks for $1 \mathrm{~min}$. The collecting tubes were weighed before and after the venom extraction in order to estimate the weight of the liquid venom obtained. After the extraction, the venom was centrifuged and stored at $-70{ }^{\circ} \mathrm{C}$ until it was used. Extraction was performed monthly in order to allow sufficient time for the tarantulas to replenish their venom supply. Analysis of venom profiles by electrophoresis was done individually and differences were not observed between specimens of the same species or between successive extractions 
from the same specimen. In this manner, venoms from six or seven extractions were used to form a pool of venom from each species for the biological assessments.

\section{Protein quantification}

The protein content of the venoms was determined by the Bradford assay [12], using a standard curve prepared with lyophilized bovine serum albumin.

\section{Toxicity in crickets}

The venom toxicity was assessed by determining the median lethal dose $\left(\mathrm{LD}_{50}\right)$ in crickets (Acheta domestica purchased from Maskota SA de CV, Mexico) of undetermined sex weighing 190-210 mg by a previously described method [13]. Briefly, venoms were assessed by thoracic injection into crickets $(n=5$, for each venom dose) at several doses $(1,3.2,10,31.6,100$, and $316 \mu$ g protein $/ \mathrm{mL}$ ). All venoms were dissolved in insect saline composed of $200 \mathrm{mM} \mathrm{NaCl}, 3.1 \mathrm{mM} \mathrm{KCl}, 5.4 \mathrm{mM} \mathrm{CaCl}, 4 \mathrm{mM} \mathrm{MgCl}$, $2 \mathrm{mM} \mathrm{NaHCO}_{3}, 0.1 \mathrm{mM} \mathrm{Na}_{2} \mathrm{HPO}_{4}, \mathrm{pH}$ 7.2. The injection volume for all crickets, including the controls that received insect saline, was $10 \mu \mathrm{L}$. Injections were performed using a $0.3 \mathrm{~mL}$-gauge insulin syringe (B-D Ultra-Fine, Terumo Medical Corporation, USA). After the injection, the crickets were placed in small plastic containers with food and water. Mortality was scored at 24 and $48 \mathrm{~h}$ post-injection. The $\mathrm{LD}_{50}$ values were interpolated by fitting log dose-response curves using non-linear regression analysis in Prism 5.0 (GraphPad Software, Inc., USA) and reported as the mean \pm SEM of three replicates.

\section{Formalin test}

Acute neurogenic and chronic inflammatory nociception were measured using the rat paw formalin test as described by Dubuisson and Dennis [14] with some modifications. Three quantities of each venom $(5,10$, and $20 \mu \mathrm{g}$ protein/paw) were dissolved in $50 \mu \mathrm{L}$ of sterile saline solution $(0.9 \% \mathrm{NaCl})$ and injected subcutaneously into the right dorsal hind paw of male Wistar rats weighing 100-120 $g$ ( $n=3$ /group). The positive control group received $50 \mu \mathrm{L}$ of $2.5 \%$ formalin, and the negative group received $50 \mu \mathrm{L}$ of saline solution through the same route of administration. During the test, each rat was placed in a transparent glass container and nociceptive behavior was quantified by counting the time of licking, flinching, and lifting of the injected hind paw. Measurements were made in two phases: the first phase (neurogenic) was evaluated during the period from 0 to $10 \mathrm{~min}$ after injection, and the second phase (inflammatory) was from 10 to $50 \mathrm{~min}$ after injection.

\section{Edematogenic activity}

To assess the edematogenic activity of venoms, rat paw edema was measured with a manual hydroplethysmometer as previously described [15]. After subplantar injection of $50 \mu \mathrm{L}$ of venom ( $40 \mu \mathrm{g}$ protein/paw) on the right hind paw of male Wistar rats weighing 100-120 $g$ ( $n=3$ /group), the rat paw edema was measured every $10 \mathrm{~min}$ in the first hour and every $30 \mathrm{~min}$ in the second hour. The positive control group received $100 \mu \mathrm{L}$ of $1 \%$ carrageenan solution prepared with distilled water, and the negative group received $50 \mu \mathrm{L}$ of saline solution through the same route of administration.

\section{Enzymatic activity}

The hyaluronidase activity was determined according to a turbidimetric method [16]. Briefly, different concentrations of venoms $(1,2.5,5,7.5,10,15,20$, and $25 \mu \mathrm{g}$ protein $/ \mathrm{mL})$, diluted in $150 \mu \mathrm{L}$ of buffer $(0.2 \mathrm{M}$ sodium acetate, $\mathrm{pH} 6.0$, containing $0.15 \mathrm{M} \mathrm{NaCl}$ ), were incubated with $100 \mu \mathrm{L}$ of substrate $(1 \mathrm{mg}$ of hyaluronic acid sodium salt from Streptococcus equi in $1 \mathrm{~mL}$ of acetate buffer) at $37{ }^{\circ} \mathrm{C}$ for $15 \mathrm{~min}$. After the incubation period, $1 \mathrm{~mL}$ of hexadecyltrimethylammonium (2.5\%) in $2 \%$ $\mathrm{NaOH}$ was added to the samples. The resulting turbidity was read at $400 \mathrm{~nm}$ in a microplate spectrophotometer (Benchmark Plus, Bio-Rad, USA) after $30 \mathrm{~min}$ of incubation at room temperature. As the reference for hyaluronidase activity, hyaluronidase from bovine testes type IV-S was used at the same concentrations as the venoms. The enzymatic activity was expressed as mean $\pm \operatorname{SEM}(n=3)$ in turbidity reducing units (TRU)/mg. One unit of activity corresponded to the amount of enzyme that produced a $50 \%$ reduction in turbidity caused by $0.1 \mathrm{mg}$ of substrate under the conditions described above.

In order to detect possible phospholipase $\mathrm{A}_{2}$ activity in the venoms $(10 \mu \mathrm{g}$ of protein), a secretory colorimetric assay kit (Cayman Chemical, USA) was used. This assay uses the 1,2-dithio analogue of diheptanoyl phosphatidylcholine as substrate. Free thiols generated upon hydrolysis of the thioester bond at the sn-2 position by phospholipases were detected using DTNB [ $5,5^{\prime}$-dithio-bis-(2-nitrobenzoic acid)]. Color changes were monitored by a Benchmark Plus microplate spectrophotometer (Bio-Rad, USA) at $414 \mathrm{~nm}$ by sampling every minute for ten minutes. For this colorimetric assay, a phospholipase $\mathrm{A}_{2}$ from bee venom was used as the control. Phospholipase $\mathrm{A}_{2}$ activity was expressed as $\mu \mathrm{mol}$ of hydrolyzed substrate/minute/mg of protein.

In addition, caseinolytic activity was assayed in order to detect possible protease activity in the venoms. It was assayed according to a previously described method [17]. Aliquots $(0.4 \mathrm{~mL})$ of $2 \%$ casein in $0.2 \mathrm{M}$ Tris- $\mathrm{HCl}$ buffer $(\mathrm{pH} 7.5)$ were incubated with different quantities of venom $(1,10,20,30,50$, and $100 \mu \mathrm{g}$ protein $/ \mathrm{mL})$ at $37{ }^{\circ} \mathrm{C}$ for $30 \mathrm{~min}$. The reaction was stopped by adding $1.5 \mathrm{~mL}$ of $0.44 \mathrm{M}$ tricholoacetic acid and allowed to stand for $30 \mathrm{~min}$. The mixture was centrifuged at $1500 \times g$ for $15 \mathrm{~min}$. An aliquot $(1 \mathrm{~mL})$ was mixed with $2.5 \mathrm{~mL}$ of $0.4 \mathrm{M}$ sodium 
carbonate and $0.5 \mathrm{~mL}$ of 1:2 diluted Folin reagent, and the color developed was read at $660 \mathrm{~nm}$. The reference for protease activity was a protease from Streptomyces griseus. Activity was expressed as $\mu \mathrm{mol}$ substrate/minute/mg of protein.

\section{SDS-Polyacrylamide Gel Electrophoresis (SDS-PAGE)}

Electrophoresis was performed as previously described [18]. Samples were diluted 1:1 in a sample buffer (BioRad, USA, Cat \# 161-0737). Samples under reducing conditions were diluted 1:1 in a sample buffer containing $\beta$-mercaptoethanol and heated at $95{ }^{\circ} \mathrm{C}$ for $5 \mathrm{~min}$. Then, 18 and $14 \%$ polyacrylamide gels, loaded with $15 \mu \mathrm{g}$ of protein, were electrophoresed at $120 \mathrm{~V}$ for $2 \mathrm{~h}$ at $4{ }^{\circ} \mathrm{C}$, using Tris-Glycine buffer ( $25 \mathrm{mM}$ Tris, $192 \mathrm{mM}$ glycine, pH 8.3; Bio-Rad, USA, Cat \# 161-0734). Protein bands were visualized using Coomasie brilliant blue R-250 staining solution (Bio-Rad, USA, Cat \# 161-0437). Molecular masses were determined by comparison with a broad-range polypeptide standard (Bio-Rad, USA, Cat \# 161-0318).

\section{Ethics committee approval}

The animal utilization was approved by the Committee of Bioethics of the School of Medicine, UAQ.

\section{Results}

\section{Venom yield}

B. epicureanum specimens yielded more venom $(14.7 \pm$ $2.6 \mathrm{mg}$ of liquid/spider; $n=6)$ than $P$. regalis $(8.7 \pm 1.1 \mathrm{mg}$ of liquid/spider; $n=6)$ and $C$. darlingi $(4.0 \pm 0.1 \mathrm{mg}$ of liquid/spider; $n=7$ ) specimens. For $B$. epicureanum the protein concentration was $3.2 \pm 0.3 \%$ of the venom weight, while for $P$. regalis it was $5.9 \pm 0.7 \%$, and $16.3 \pm 2.4 \%$ for C. darlingi.

\section{Toxicity on crickets}

The results of the insecticidal activity on crickets showed that the $\mathrm{LD}_{50}$ values of the venoms of $P$. regalis and B. epicureanum were similar and the lethality of both venoms increased with time. The venom of $C$. darlingi was significantly less lethal than the other venoms (Table 1, Fig. 1). As for $P$. regalis and B. epicureanum venoms, it was observed that doses equal to or higher than $10 \mu \mathrm{g}$ protein $/ \mathrm{g}$ induced paralysis within $2 \mathrm{~min}$, while doses equal to or higher than $31.6 \mu \mathrm{g}$ protein/g of $C$. darlingi venom induced paralysis within $10 \mathrm{~min}$. However, all crickets paralyzed with $C$. darlingi venom at $31.6 \mu \mathrm{g}$ protein/g completely recovered after $24 \mathrm{~h}$.

\section{Formalin test}

The results obtained with this test showed that in both phases (at doses of 5, 10, and $20 \mu \mathrm{g} /$ rat hind-paw) the venoms of $P$. regalis, $C$. darlingi, and B. epicureanum did
Table $1 \mathrm{LD}_{50}$ values estimated from injection of $P$. regalis, $C$. darlingi, and B. epicureanum venoms into crickets

\begin{tabular}{lll}
\hline Venoms & \multicolumn{2}{c}{ Time post-injection } \\
\hline P. regalis & 24 hours & 48 hours \\
C. darling & $20.6 \pm 6.2$ & $5.23 \pm 3.1$ \\
B. epicureanum & $119.4 \pm 29.5$ & $120.2 \pm 32.3$ \\
\hline
\end{tabular}

Values represent the mean \pm standard error $(n=3)$

not induce nociceptive behavior in rats when compared to the negative control (saline solution). On the contrary, the formalin group was significantly different from all experimental groups and the negative control in the first and second phases (Fig. 2).

\section{Edematogenic activity}

Assessment of the venoms' edematogenic activity by subplantar injection of $40 \mu \mathrm{g}$ of protein/rat showed that they induce a similar time-dependent increase in paw volume (Fig. 3). The maximum responses were observed at $10 \mathrm{~min}$ after administration, decreasing at approximately $60 \mathrm{~min}$. However, $P$. regalis venom induced an evident redness immediately after administration. Carrageenan, used as a positive control, induced an increase in paw volume similar to that induced by the venoms but it did not decrease during the experiment. The negative control $(50 \mu \mathrm{L}$ of saline solution) did not induce a detectable response.

\section{Enzymatic activity}

The hyaluronidase activity of $P$. regalis venom $(27.6 \pm 0.9$ TRU/mg) was significantly higher than that of $C$. darlingi (99.7 $\pm 1.9 \mathrm{TRU} / \mathrm{mg})$ and B. epicureanum $(99.6 \pm 1.6 \mathrm{TRU} /$ $\mathrm{mg}$ ). The hyaluronidase from bovine testes type IV-S, used

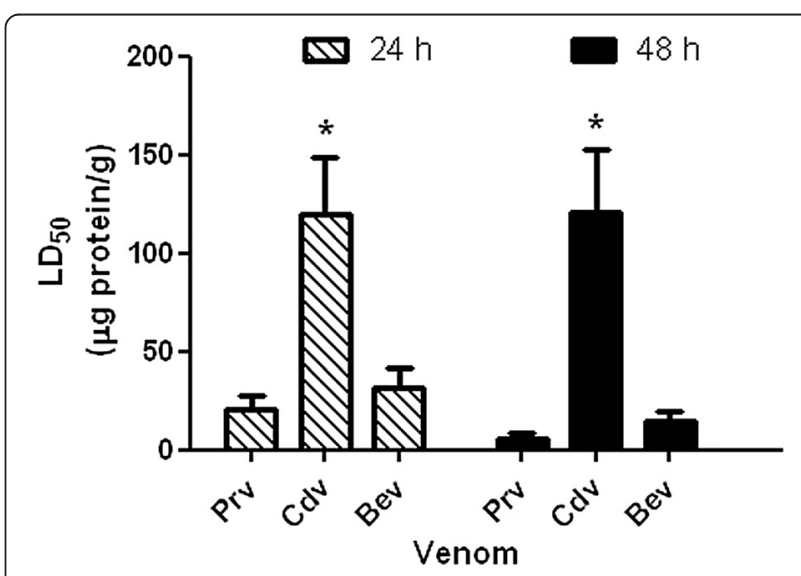

Fig. 1 Comparison of $L_{50}$ values estimated from the injection of $P$. regalis (Prv), C. darlingi (Cdv), and B. epicureanum (Bev) venoms into crickets. Values represent the mean \pm standard error $(n=3)$. *Significant difference $(p<0.05)$ 


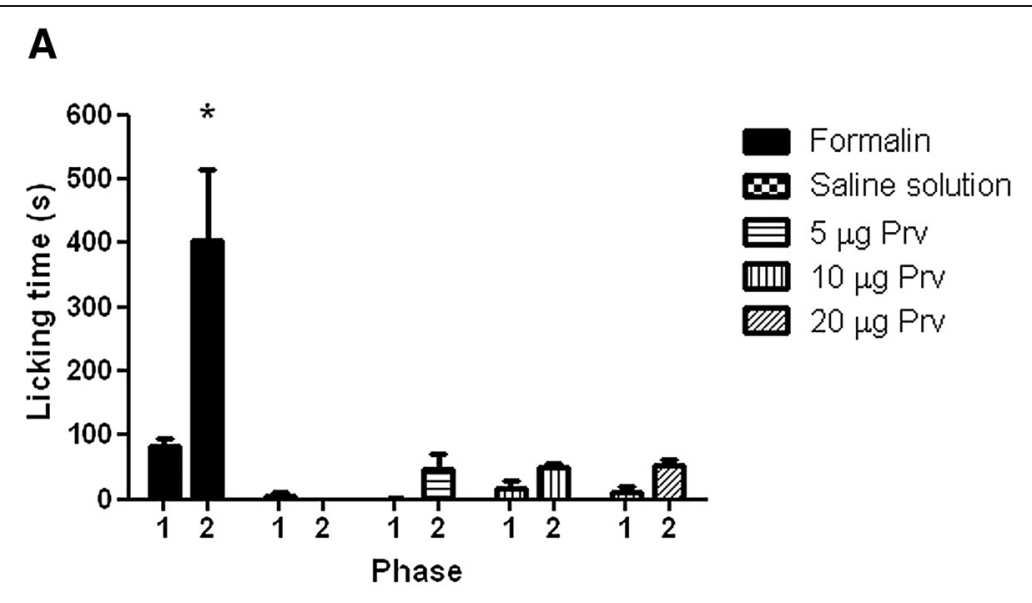

\section{B}
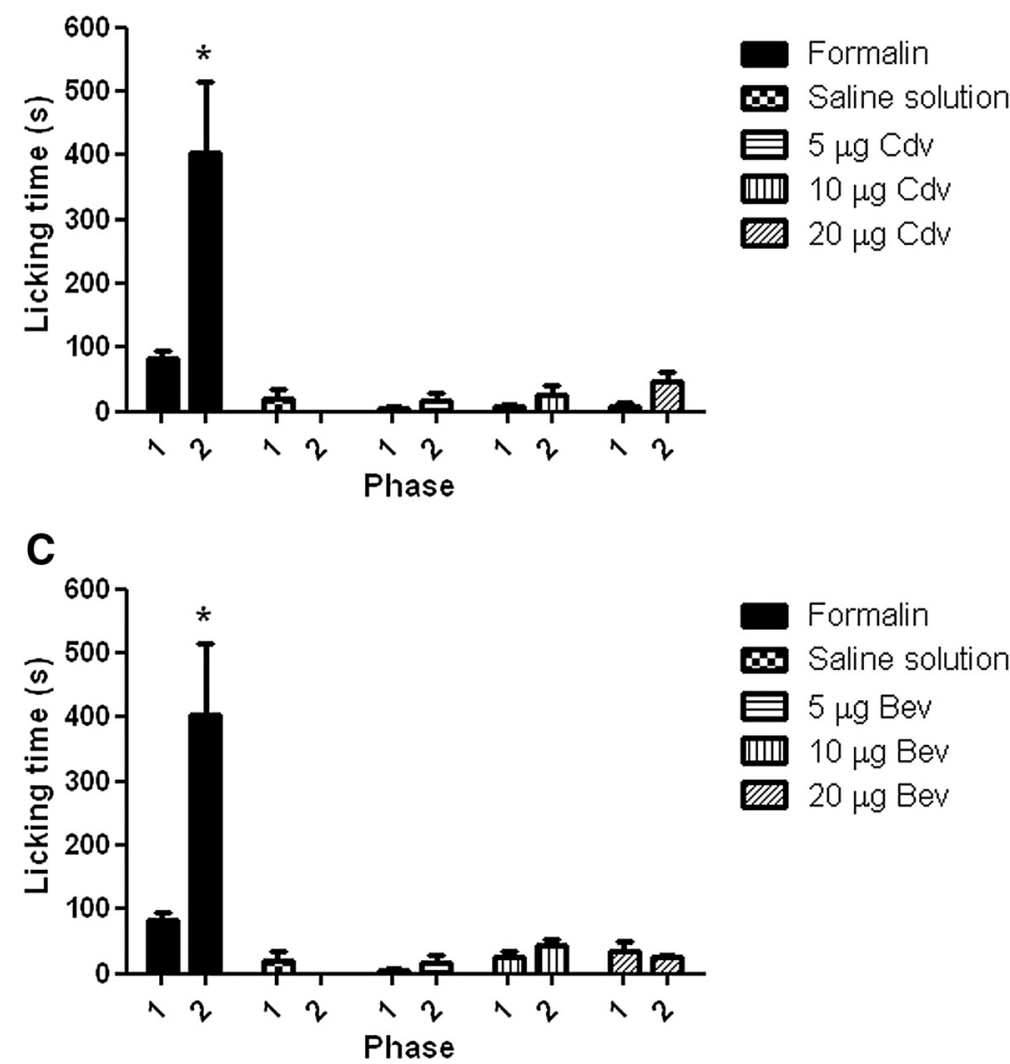

Fig. 2 Formalin test for assessment of the nociceptive activity in rats of a $P$. regalis, $\mathbf{b}$ C. darlingi, and $\mathbf{c} B$. epicureanum venoms at three different doses (5, 10 , and $20 \mu \mathrm{g}$ protein/paw). Nociceptive behavior in phase 1 (0-10 min post-injection) and phase 2 (10-50 min post-injection) was scored as the amount of time spent licking the injected paw. *Significant difference when compared with the negative control injected with saline solution $(p<0.05)$

as a control, induced an enzymatic activity of $149.5 \pm 1.4$ TRU/mg under these conditions. The venom of $P$. regalis reached maximum activity at a concentration of $7.5 \mu \mathrm{g} / \mathrm{mL}$, while the other venoms showed maximum activity between 20 and $25 \mu \mathrm{g} / \mathrm{mL}$ (Fig. 4). As expected, it was found that the venoms do not display phospholipase $\mathrm{A}_{2}$ or caseinolytic activity. In these assays, a phospholipase $\mathrm{A}_{2}$ from bee venom displayed an activity of $3.18 \pm 1.0 \mu \mathrm{mol} / \mathrm{minute} / \mathrm{mg}$ and a protease from Streptomyces griseus displayed an activity of $980.4 \pm 5.2 \mu \mathrm{mol} / \mathrm{minute} / \mathrm{mg}$.

\section{SDS-PAGE analysis}

Analysis by electrophoresis provides a preliminary overview of the proteins present in the venoms. Cdv and Prv profiles do not show important differences under reducing and not reducing conditions, and it is evident that these venoms 


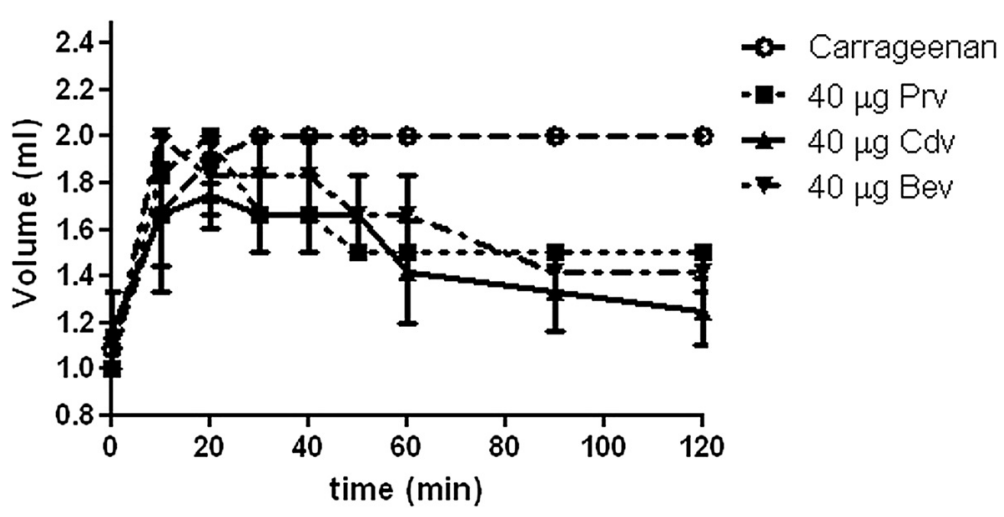

Fig. 3 Volume of rat paw edema induced by subplantar injection of $40 \mu \mathrm{g}$ of $P$. regalis (Prv), C. darlingi (Cdv), and B. epicureanum (Bev) venom protein. The positive control group received $100 \mu \mathrm{L}$ of $1 \%$ carrageenan solution, while the negative control group received $50 \mu \mathrm{L}$ of saline solution (this did not induce detectable volume changes). Values represent the mean \pm standard error $(n=3)$

contain bands in two main regions, representing two ranges of mass: $2-15 \mathrm{kDa}$ and $\sim 40$ to $\sim 100 \mathrm{kDa}$. In contrast, Bev profile evidently change under reducing conditions (Fig. 5a).

\section{Discussion}

The relative toxicity of tarantula venoms is extremely variable. These spiders' typical prey mainly consists of insects and other arthropods, but the venoms from some species have been reported to be lethal to pigeons, guinea pigs, rabbits, mice, rats, amphibians, snakes, lizards, and dogs $[1,8]$. It is important to consider that the venom of each tarantula contains a specific mixture of components that bind to targets and may vary considerably, which was probably an evolutionary outcome that depended on the diversity of prey species in their environment. A comparative study on mice, using the venoms of 55 theraphosid spiders from several geographic areas,

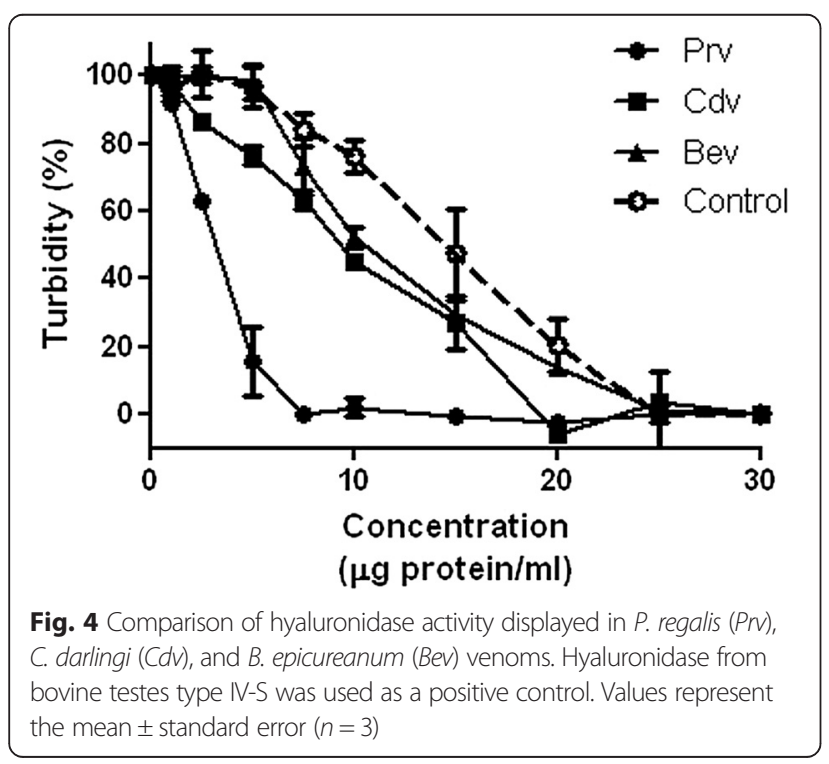

produced results that suggest an apparent higher toxicity of venoms from arboreal genera such as Heteroscodra (native to Africa), Stromatopelma (native to Africa), and Poecilotheria (native to Sri Lanka and India) [1].

In this study, we found that $P$. regalis venom was slightly more lethal to crickets than that of B. epicureanum and significantly more lethal than $C$. darlingi venom. The higher toxicity of $P$. regalis venom could be an adaptive advantage used to rapidly paralyze and kill prey in an aerial environment. The fact that the venom from the Mexican tarantula was more effective in killing crickets than the venom from the aggressive African tarantula is consistent with other studies. For example, it was found that the venoms from the Mexican tarantulas Brachypelma harmorii and B. albiceps were slightly more lethal to crickets than the venoms of several Australian tarantulas [19].

An interesting observation in the assessment of the insecticidal activity of these venoms was the capacity of $C$. darlingi venom to induce reversible paralysis. It is well known that several venomous animals produce toxins that modulate the activity of ion channels in order to capture their prey. Tarantula venoms include peptide neurotoxins that consist of 33-41 amino acid residues with three disulfide bridges that form an inhibitor cystine knot motif, defined as an antiparallel $\beta$-sheet stabilized by a cystine knot $[1,6,20]$. Many of these neurotoxins work together to provoke a characteristic paralysis on several types of prey.

At present, 27 of the 95 neurotoxins from tarantula venoms listed in ArachnoServer target voltage-gated sodium (Nav) channels, most of them acting by inhibiting inactivation. In fact, three of these toxins were found in the venom of the African tarantula Ceratogyrus marshalli: $\beta$-theraphotoxin- $\mathrm{Cm} 1 \mathrm{a}$ and $\beta$-theraphotoxin- $\mathrm{Cm} 1 \mathrm{~b}$ modulate several subtypes of $\mathrm{Nav}$ channels (Nav1.1, Nav1.2, Nav1.4, Nav1.5, and Nav1.8) by shifting the voltage dependence of channel activation to more depolarized potentials and by blocking the inward component of the sodium 


\section{A}

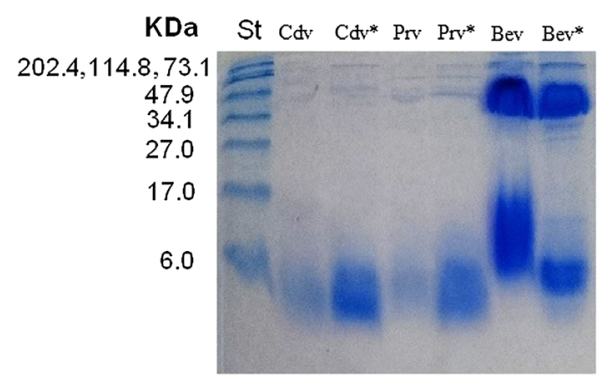

B

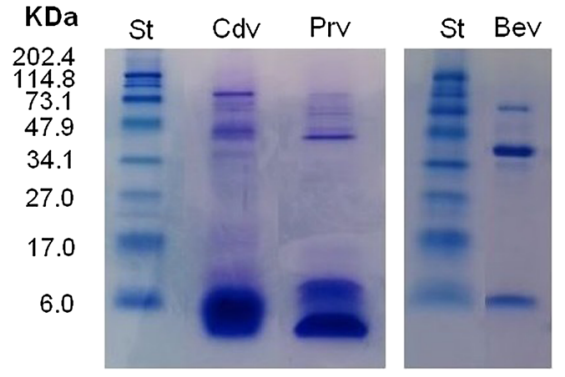

Fig. 5 a. SDS-PAGE gel (18\% acrylamide) showing the protein profiles of P. regalis (Prv), C. darlingi (Cdv) and B. epicureanum (Bev) venoms. Prv*, $\mathrm{Cdv}^{*}$ and $\mathrm{Bev}^{*}$ correspond to the venoms under reducing conditions. b. SDS-PAGE gel (14 \% acrylamide) showing the protein profiles of the venoms under reducing conditions. The protein profiles were compared with a broad-range polypeptide standard (St), and the masses of the molecular weight markers (in kDa) are shown on the left of the gels. Protein bands were visualized with Coomasie blue

current, while $\beta$-theraphotoxin-Cm2a modulates Nav1.5 and Nav1.8 channels [6]. A more potent immobilization is promoted by the potassium channel blockers through the prevention of nerve repolarization; 43 of these toxins have been reported in ArachnoServer. Moreover, 36 tarantula toxins have been reported to be irreversible calcium channel blockers. Some of these toxins can target different types of channels (Nav, Kv, and/or Cav) and appear to function through a similar mechanism; they are known as promiscuous toxins $[1,6]$.

The complexity of tarantula venoms results in a synergistic action that may produce fast paralysis and death in prey. Therefore, it is probable that the mixture of neurotoxins contained in the venom of $C$. darlingi is not capable of inducing a fast and permanent paralysis like that of $P$. regalis. Some tarantula neurotoxins induce reversible paralysis in specific animal models. For example, U1-theraphotoxin-Cv1a, found in the venom of Coremiocnemis valida (Singapore brown tarantula), induces reversible paralysis in crickets, but not in cockroaches and mice [6]; and huwentoxin- $\mathrm{V}$, purified from the venom of Selenocosmia huwena (Chinese bird spider), can reversibly paralyze locusts and cockroaches for several hours [21].

Despite the fact that theraphosid spider bites are considered to be harmless to humans, there is evidence to support the idea that bites of Poecilotheria spp. are of medical importance $[1,8,10,11]$. In a recent literature review of bite reports of Poecilotheria spp., most of them referred to $P$. regalis. Symptoms included local swelling, erythema, and moderate to severe pain. Of these bites, $58 \%$ caused generalized muscle cramps that began on average $10 \mathrm{~h}$ after the incident and persisted for 1-14 days. Further symptoms were burning sensation, heat, fever, myalgia, heavy breathing, increased heart rate, and even brief loss of consciousness [11]. A possible explanation for the higher toxicity of the Poecilotheria species in humans is associated with the quantity of venom injected.
In a comparative study, the quantity of venom milked from several theraphosid species was compared and it was observed that an average Poecilotheria species yields approximately $12 \mu \mathrm{L}$ more venom than other theraphosids [22]. In the present study, the weight of milked venom was measured and it was observed that B. epicureanum specimens yielded on average approximately two-fold more venom than $P$. regalis specimens, while C. darlingi specimens yielded four-fold less venom than B. epicureanum specimens. However, there was no significant difference in the amount of protein contained in the venom milked from the three species. It seems that the protein content is similar, but it is more concentrated in $C$. darlingi venoms. Thus, it is quite possible that the toxicity of $P$. regalis venom is due to the mixture of toxins rather than to the quantity of venom injected.

Many components of animal venoms are used defensively to ward off predators or competitors by inflicting pain [23]. Depending on the species, tarantula bite victims experience moderate or severe pain $[10,11]$. This variable symptom may be attributable to a combination of a mechanical injury caused by the spider's large fangs, a slightly acidic $\mathrm{pH}$ (usually close to 5), and the presence of some components such as biogenic amines (serotonin and histamine), adenosine, adenosine triphosphate, and inhibitor cystine knot peptides (vanillotoxins and DkTx), which specifically activate the noxious heat-sensing transient receptor potentiating (TRP) V1 receptor that is also the target of capsaicin, the painful toxin in 'hot' chili peppers [1, 23-25].

The formalin test is widely used to evaluate inflammatory and non-inflammatory pain in rats [14]. The first phase of the test is believed to result from the direct activation of primary afferent sensory neurons; this response is associated with direct activation of TRP channels present in nociceptors [26]. It has been proposed that the second phase reflects the combined effects of TRP channel activation and 
the development of an inflammatory response that prolongs the pain triggered by mediators such as interleukins $1 \beta, 6$, and 8 , TNF- $\alpha$, eicosanoids, and nitric oxide $[27,28]$. In this study, the results obtained in the formalin test indicated that the $P$. regalis, $C$. darlingi, and B. epicureanum venoms did not produce a significant nociceptive effect at the tested doses. However, all three venoms tested in this study induced inflammatory responses. Similar results were observed with the venom of the Brazilian theraphosid spider Acanthoscurria paulensis [29]. The weak nociceptive responses observed with these venoms may be due to the presence of analgesic toxins.

In contrast with theraphosid toxins that induce pain by activating TRPV1 receptors, there are other theraphosid toxins that have analgesic properties. For example, $\mu$-TRTX-Hhn1b, isolated from the venom of Ornithoctonus hainana, and huwentoxin-IV, isolated from the venom of Ornithoctonus huwena, are Nav1.7 channel inhibitors that efficiently alleviate acute inflammatory pain and chronic neuropathic pain in animals [30, 31]. Mechanotoxin 4, isolated from Grammostola rosea venom, reduces mechanical and neuropathic pain by blocking stretch-activated cation channels [32]. Psalmotoxin 1, isolated from the venom of Psalmopoeus cambridgei, has very potent analgesic properties against thermal, mechanical, chemical, inflammatory, and neuropathic pain in rodents by blocking acid-sensing ion channel 1a; this results in the activation of the enkephalin pathway [33]. Protoxin-I, obtained from the venom of Thrixopelma pruriens, is the first known peptide antagonist of the nociceptor ion channel TRPA1 [34].

Enzymes are important components of the venoms of several animals, and hyaluronidase activity is widely displayed in spider venoms [35]. The substrate for hyaluronidases is the hyaluronic acid, a mucopolysaccharide that is the major constituent of the extracellular matrix [36]. It is believed that the presence of these enzymes in animal venoms helps to distribute other venom components by hydrolyzing connective tissue [35]. In this study, we found that all three venoms induce hyaluronidase activity. An important observation is that $P$. regalis venom induces significantly higher hyaluronidase activity, which could be related to its higher toxicity. We also found that the venoms do not display phospholipase $\mathrm{A}_{2}$ or caseinolytic activity, in agreement with previous studies that suggest that neither phospholipase A nor protease activity is present in tarantula venoms $[35,37]$.

Finally, analysis by electrophoresis reveals that the $C$. darlingi and $P$. regalis venoms contain bands in two regions in different proportions. One region consists of small peptides $(2-15 \mathrm{kDa})$ that are mainly neurotoxins [1]. The other region consists of proteins with masses between 40 and $100 \mathrm{kDa}$ comprising hyaluronidases $(39-43 \mathrm{kDa})$ and other components [38-40]. The profiles of the venoms showed important differences in their compositions, mainly in the venom of B. epicureanum, in which it can be observed that the profile of this venom change under reducing conditions. However, further proteomic analysis is necessary to improve these differences.

\section{Conclusions}

This study demonstrates that these theraphosid spiders of different habitats produce venoms with diverse activities. It is observed that $P$. regalis venom displays a high level of hyaluronidase activity, which may be associated with its potentially medically significant bite.

\section{Competing interests}

The authors declare that they have no competing interests.

\section{Authors' contributions}

All authors performed the experiments. AGA conceived, designed, coordinated and wrote the manuscript. All authors read and approved the final manuscript.

\section{Acknowledgments}

This work was supported by grants FOFI-UAQ FCQ-2014-23 from UAQ and CB-2013-01/223591 from the National Council on Science and Technology (CONACYT) to A. García-Arredondo, and by grant INFR-2014-01-226186 from CONACYT to A. Rojas. L. Rodríguez-Rios and L. F. Díaz-Peña acknowledge scholarships from CONACYT. R. Vega-Ángeles acknowledge a scholarship from UAQ

Received: 17 January 2015 Accepted: 18 May 2015

Published online: 17 June 2015

\section{References}

1. Escoubas P, Rash L. Tarantulas: eight-legged pharmacists and combinatorial chemists. Toxicon. 2004:43(5):555-74.

2. Deng $M$, Luo X, Xiao Y, Sun Z, Jiang L, Liu Z, et al. Huwentoxin-XVI, an analgesic, highly reversible mammalian $\mathrm{N}$-type calcium channel antagonist from Chinese tarantula Ornithoctonus huwena. Neuropharmacology. 2014;79:657-67.

3. Kalia J, Milescu M, Salvatierra J, Wagner J, Klint JK, King GF, et al. From foe to friend: using animal toxins to investigate ion channel function. J Mol Biol. 2014;427(1):158-75.

4. Klint JK, Senff S, Rupasinghe DB, Er SY, Herzig V, Nicholson GM, et al. Spider-venom peptides that target voltage-gated sodium channels: pharmacological tools and potential therapeutic leads. Toxicon. 2012;60(4):478-91

5. World Spider Catalog. World spider catalog, version 15.5. Natural History Museum, Bern. 2014. http://wsc.nmbe.ch, version 15.5. Accessed on 12 Dec 2014.

6. Herzig V, Wood DLA, Newell F, Chaumeil P-A, Kaas Q, Binford GJ, et al. Arachnoserver 2.0, an updated online resource for spider toxin sequences and structures. Nucleic Acids Res. 2011;39:D653-7.

7. Rojo R. Las tarántulas de México: pequeños gigantes incomprendidos. CONABIO Biodiversitas. 2004;56:7-11.

8. Isbister GK, Seymour JE, Gray MR, Raven RJ. Bites by spiders of the family Theraphosidae in humans and canines. Toxicon. 2003;41(4):519-24.

9. De Haro L, Jouglard J. The dangers of pet tarantulas: experience of the Marseilles Poison Centre. J Toxicol Clin Toxicol. 1998;36(1-2):51-3.

10. Ahmed N, Pinkham M, Warrell DA. Symptom in search of a toxin: muscle spasms following bites by Old World tarantula spiders (Lampropelma nigerrimum, Pterinochilus murinus, Poecilotheria regalis) with review. QJM. 2009:102(12):851-7.

11. Fuchs J, von Dechend M, Mordasini R, Ceschi A, Nentwig W. A verified spider bite and review of the literature confirm Indian ornamental tree spiders (Poecilotheria species) as underestimated theraphosids of medical importance. Toxicon. 2014;77:73-7.

12. Bradford MM. A rapid and sensitive method for the quantitation of microgram quantities of protein utilizing the principle of protein-dye binding. Anal Biochem. 1976;72(1-2):248-54. 
13. Herzig V, Khalife AA, Chong Y, Isbister GK, Currie BJ, Churchill TB, et al. Intersexual variations in Northern (Missulena pruinosa) and Eastern ( $M$. bradleyi) mouse spider venom. Toxicon. 2008;51(7):1167-77.

14. Dubuisson D, Dennis SG. The formalin test: a quantitative study of the analgesic effects of morphine, meperidine, and brain stem stimulation in rats and cats. Pain. 1977:4:161-74

15. Mortari MR, do Couto LL, dos Anjos LC, Mourão CBF, Camargos TS, Vargas JÁ, et al. Pharmacological characterization of Synoeca cyanea venom: an aggressive social wasp widely distributed in the Neotropical region. Toxicon. 2012;59(1):163-70.

16. Di Ferrante N. Turbidimetric measurement of acid mucopolysaccharides and hyaluronidase activity. J Biol Chem. 1956;220(1):303-6.

17. Murata Y, Satake M, Szuki T. Studies on snake venom. XII. Distribution of proteinase activities among Japanese and Formosan snake venoms. J Biochem. 1963;53(6):431-43.

18. Laemmli UK. Cleavage of structural proteins during the assembly of the head of bacteriophage T4. Nature. 1970;227:680-5.

19. Gentz MC, Jones A, Clement H, King GF. Comparison of the peptidome and insecticidal activity of venom from a taxonomically diverse group of theraphosid spiders. Toxicon. 2009;53(5):496-502.

20. Pallaghy PK, Nielsen KJ, Craik DJ, Norton RS. A common structural motif incorporating a cystine knot and a triple-stranded $\beta$-sheet in toxic and inhibitory polypeptides. Protein. 1994;3(10):1833-9.

21. Zhang PF, Chen P, Hu WJ, Liang SP. Huwentoxin-V, a novel insecticidal peptide toxin from the spider Selenocosmia huwena, and natural mutant of the toxin: indicates the key amino acid residues related to the biological activity. Toxicon. 2003;42(1):12-20.

22. Herzig V. Update zum DeArGe-Spinnengiftprojekt. Arachne. 2010;15(4):26-31.

23. Cromer BA, Mclntyre P. Painful toxins acting at TRPV1. Toxicon. 2008;51(2):163-73.

24. Siemens J, Zhou S, Piskorowski R, Nikai T, Lumpkin EA, Basbaum Al, et al. Spider toxins activate the capsaicin receptor to produce inflammatory pain. Nature. 2006;444(7116):208-12.

25. Bohlen CJ, Priel A, Zhou S, King D, Siemens J, Julius D. A bivalent tarantula toxin activates the capsaicin receptor, TRPV1, by targeting the outer pore domain. Cell. 2010;141(5):834-45.

26. McNamara CR, Mandel-Brehm J, Bautista DM, Siemens J, Deranian KL, Zhao $M$, et al. TRPA1 mediates formalin-induced pain. Proc Natl Acad Sci USA. 2007;104(33):13525-30.

27. Chichorro JG, Lorenzetti BB, Zampronio AR. Involvement of bradykinin, cytokines, sympathetic amines and prostaglandins in formalin-induced orofacial nociception in rats. Br J Pharmacol. 2004;141(7):1175-84.

28. Hunskaar S, Hole K. The formalin test in mice: dissociation between inflammatory and non-inflammatory pain. Pain. 1987;30(1):103-14.

29. Mourão CB, Oliveira FN, e Carvalho AC, Arenas CJ, Duque HM, Gonçalves JC, et al. Venomic and pharmacological activity of Acanthoscurria paulensis (Theraphosidae) spider venom. Toxicon. 2013;61:129-38.

30. Liu Y, Tang J, Zhang Y, Xun X, Tang D, Peng D, et al. Synthesis and analgesic effects of $\mu$-TRX-Hhn1b on models of inflammatory and neuropathic pain. Toxins (Basel). 2014;6(8):2363-78.

31. Liu Y, Wu Z, Tang D, Xun X, Liu L, Li X, et al. Analgesic effects of Huwentoxin-IV on animals models of inflammatory and neuropathic pain. Protein Pept Lett. 2014;21(2):153-8.

32. Park SP, Kim BM, Koo JY, Cho H, Lee CH, Kim M, et al. A tarantula spider toxin, GsMTx4, reduces mechanical and neuropathic pain. Pain. 2008;137(1):208-17.

33. Mazzuca M, Heurteaux C, Alloui A, Diochot S, Baron A, Voilley N, et al. A tarantula peptide against pain via ASICla channels and opioid mechanisms. Nat Neurosci. 2007:10:943-5.

34. Gui J, Liu B, Cao G, Lipchik AM, Perez M, Dekan Z, et al. A tarantula-venom peptide antagonizes the TRPA1 nociceptor ion channel by binding to the S1-S4 gating domain. Curr Biol. 2014;24(5):473-83.

35. Rash LD, Hodgson WC. Pharmacology and biochemistry of spider venoms. Toxicon. 2002; 40(3):225-54.

36. Kreil G. Hyaluronidases-a group of neglected enzymes. Protein Sci. 1995;4(9):1666-9.

37. Perret BA. Proteolytic activity of tarantula venoms due to contamination with saliva. Toxicon. 1977;15(6):505-10.

38. Sutti R, Tamascia ML, Hyslop S, Rocha-e-Silva TA. Purification and characterization of a hyaluronidase from venom of the spider Vitalius dubius (Araneae, Theraphosidae). J Venom Anim Toxins incl Trop Dis. 2014;20(1):2.
39. Clement H, Olvera A, Rodríguez M, Zamudio F, Palomares LA, Posssani LD, et al. Identification, cDNA cloning and heterologous expression of a hyaluronidase from the tarantula Brachypelma vagans venom. Toxicon. 2012;60(7):1223-7.

40. Schanbacher FL, Lee CK, Wilson IB, Howell DE, Odell GV. Purification and characterization of tarantula, Dugesiella hentzi (girard) venom Hyaluronidase. Comp Biochem Phys B. 1973;44(2):389-96.

\section{Submit your next manuscript to BioMed Central and take full advantage of:}

- Convenient online submission

- Thorough peer review

- No space constraints or color figure charges

- Immediate publication on acceptance

- Inclusion in PubMed, CAS, Scopus and Google Scholar

- Research which is freely available for redistribution 